\title{
Commercial dressings for burns versus sweet ancient remedy
}

\author{
Livia Puljak - Lorenzo Moja · Gian Franco Gensini · \\ Roberto Gusinu $\cdot$ Andrea A. Conti
}

Published online: 20 December 2008

(C) SIMI 2008

\section{The methodologist's point of view}

\section{Livia Puljak, Lorenzo Moja}

In the heart of your house, one foggy evening, you are cooking what all the world should repute as a memorable dinner; you invited some new colleagues from the hospital, which makes you feel slightly nervous. While thinking about the last table decorations you look into the oven at the big pan. Food needs your attention. You take a spoon and start to stir the ingredients but... inadvertently you burn yourself. There are few minutes before the guests will start to ring your door. What you should do?

\section{Puljak}

University of Split School of Medicine,

Soltanska 2, 21000 Split, Croatia

e-mail: livia@mefst.hr

\section{Moja $(\bowtie)$}

Italian Cochrane Center,

Mario Negri Institute for Pharmacological Research,

Via La Masa 19, 20156 Milan, Italy

e-mail: moja@marionegri.it

\section{G. F. Gensini}

Department of Critical Care Medicine and Surgery,

University of Florence and Azienda Ospedaliero-Universitaria

Careggi, Florence, Italy

e-mail: g.gensini@dac.unifi.it

R. Gusinu

DAI Cardiologico e dei Vasi Azienda Ospedaliero-Universitaria Careggi, Florence, Italy

\section{A. A. Conti}

Department of Critical Care Medicine and Surgery,

University of Florence and Don Carlo Gnocchi Foundation,

IRCCS, Florence, Italy
There are two options: the first deals with the home remedy, a natural cure, and it requires you to open your cupboard (looking for honey); the second deals with modern marketed drugs and it requires you to go to the nearest pharmacy to buy a dressing. The solution deals with the comparative efficacy of these medicines. Which should be better?

The latest issue of the Cochrane Database of Systematic Reviews offers two topical reviews dealing with this subject. In the first study, honey is evaluated for wound healing [1], and in the other, different dressings are studied for their healing properties [2]. Doctors and consumers are increasingly demanding more separation between marketing campaign to sustain products, superstition, myth remedies and evidence. In other words, the community is calling for disentanglement of evidence and folkloristic practice: these disentanglements regard both conventional medicines and nature's drugs. The results of these disentanglements sometimes are surprising.

The sweet evidence revealed

Jull et al. found that honey may improve healing times in mild to moderate superficial and partial thickness burns compared with some conventional dressings [1]. This Cochrane systematic review included nine trials that evaluated honey as a treatment for superficial, partial and mixed depth (partial and full thickness) burns compared to conventional dressings, early excision, silver sulfadiazine and several unconventional dressings. However, with the exception of one trial, all the reports of burn trials were single-author trials, and all the reports originated from a single study centre, which may have impact on study quality, replicability and confidence, eventually $[3,4]$. 
When compared to conventional dressings for the treatment of partial thickness burns, where the outcome were mean days to healing, weighted mean difference (WMD) was -4.68 days $(95 \% \mathrm{CI}-5.09$ to -4.28 days) in favour of honey $[5,6]$. One trial compared early tangential excision and skin grafting with honey dressings in seriously injured patients for the treatment of mixed partial and full thickness burns. Mean time to healing was 32 days in the honey-treated group and 18.4 days in the comparison group (WMD 13.6 days, 95\% CI 10.02-17.18 days), significantly favouring early excision and skin grafting [7]. Honey compared with silver sulfadiazine did not reveal significant difference between these two interventions (WMD -4.37 days, $95 \%$ CI -8.94 to 0.19 days) [8].

\section{Unconventional solutions}

Three trials compared honey with natural dressing, the most unconventional being boiled potato peel dressing. After preliminary trials in year 1985 found that potato peel is suitable as a burn wound dressing in developing countries because of its promotion of epithelial growth and availability [9], more histological and clinical studies have been made that further supported its usefulness $[10,11]$. In a trial included in the Cochrane review, 100 participants with partial thickness burns were recruited and compared honey to treatment with boiled potato peel [12]. The findings clearly favoured the honey: mean time to healing was 10.4 days in the honey-treated group and 16.2 days in the potato peel group (MD -5.8 days, $95 \% \mathrm{CI}-6.88$ to 4.92 days).

Both the remaining two trials recruited participants with partial thickness burns [13, 14]. In comparison with amniotic membranes, there was no significant mean difference (95\% CI -0.88 to 4.68 days) between this intervention and honey [13]. The second trial compared honey with honey-plus (a derivative), which consists of unprocessed undiluted honey with added vitamins $\mathrm{C}$ and $\mathrm{E}$, and polyethylene glycol. Significant mean difference of 1.9 days was found in favour of the honey-plus (1.9 days, 95\% CI 0.59-3.21 days) [14].

Potato peel and honey are not the only edible interventions for pain described in the literature; in a trial unrelated to this Cochrane review, banana leaf dressing was found to be of equal efficacy to potato peel bandage in protecting the wounds and aiding healing [15]. Authors of this trial state that banana leaf dressing is 11 times cheaper than potato peel dressing; banana plants can be easily grown; the leaves are easily available throughout the year; the leaves of banana are large and thus offering larger surface area and the surface is nonadherent, waxy and cool. The banana leaf dressing can be prepared very easily with little training and it supposedly is the cheapest dressing available today [15]. So, we may see randomised controlled trials in the near future by comparing banana leaf dressing with honey as a treatment of burns.

\section{Honey's healing properties}

Interest in honey as a wound management intervention has grown recently, largely due to the growing clinical problem of antibiotic-resistant bacteria and the combined difficulties for the practitioner in managing chronic wound types, such as burns, leg ulcers or surgical wounds, that may become infected, for example, with methicillin-resistant Staphylococcus aureus or Pseudomonas. The associated costs of treating such wounds are escalating as a result.

Although honey is hailed by the literature as a sound wound management intervention, modern medical practitioners may hesitate to apply honey for local treatment of wounds, because it sounds too alternative, or because of the suspicious messiness of such local application. Moreover, secondary infectious disease may be caused by contamination of honey with microorganisms $[7,16]$. While the use of honey as a wound dressing has been recognised, at least since Egyptian times circa 2,000 BC, it is only more recently, due to the development and licensing of modern honey wound dressings, that such dressings have become more widely available and used in wound management [17, $18]$.

Honey works differently from antibiotics, which attack the bacteria's cell wall or inhibit intracellular metabolic pathways. Honey is hygroscopic, meaning that it draws moisture out of the environment and thus dehydrates bacteria. Its sugar content is also high enough to hinder the growth of microbes, but the sugar content alone is not the sole reason for honey's antibacterial properties. When honey is diluted with water, reducing its high sugar content, it still inhibits the growth of many different bacterial species that cause wound infections. Because of its high sugar content, honey also prevents pain on dressing changes, as it keeps the wound surface moist by mobilising the oedema from the surrounding tissues. Honey also has antiinflammatory properties [18]. All this, together with evidence from the Cochrane review, makes honey a cheap and simple alternative to conventional dressings, which practitioners should be aware of.

\section{Best among the commercial dressings}

Another Cochrane review analysed a total of 26 randomised controlled trials that evaluated whether any type of dressing from the many now commercially available is more effective in promoting healing and minimising discomfort and infection for patients with superficial and partial thickness burns [2]. A number of dressings appear to 
have some benefits over other products in burn management, and this benefit relates to time to wound healing, the number of dressing changes and the level of pain experienced. Although not all the included studies showed difference between compared interventions, the results indicate that burns dressed with hydrogels $[19,20]$, siliconcoated dressings [21, 22], biosynthetic dressings [23-26] and antimicrobial dressings [27-29] healed more rapidly than those dressed with silver sulphadiazine or chlorhexidine-impregnated gauze dressings.

The results for hydrocolloids and polyurethane dressings also suggest an improved rate of healing $[30,31]$. There was no evidence that fibre dressings improve the rates of healing compared with silver sulphadiazine [32]. Also, there was no evidence of a difference in healing time between biosynthetic dressings and hydrocolloids [33].

\section{Conclusion}

In these two reviews, dressings and honey are very similar in terms of experiments, study quality and results. What is often different is the prejudice against grandma remedies. Evidence contrary to accepted wisdom regards conventional and unconventional medicines equally. Existing evidence can guide practitioners in choosing alternatives to therapies that they usually prescribe for mild burns. Despite the increase in the types of commercially available dressings, since circa 2,000 BC, honey is still a valid remedy. Conventional dressings are relatively cheap, but in developing countries, every penny counts; so, efficacy and availability of honey should be key drivers of the decisionmaking process. Where price is not an issue, and practitioners can choose from a wide array of commercially available dressings for wounds, evidence should be consulted when considering a certain type of dressing for a patient.

Now, coming back to your dinner, before a colleague rings the calling bell near your door, what you should do? Honey or the nearest pharmacy?

\section{A clinician's point of view}

\section{Gian Franco Gensini, Roberto Gusinu, Andrea A. Conti}

Honey, a sweet substance elaborated by honey bees, and coming from the nectar of flowers, has been considered as a curative remedy from time immemorial [34]. Primitive men collected honey for eating and therapeutic purposes, and the term "honey" is quoted more than fifty times in the King James version of the Holy Bible. However, only in recent times, the precise mechanisms accounting for the healing characteristics of honey have been, at least partially, elucidated. In the 1960s, evidence was provided regarding the fact that moist wounds healed more quickly, even if a moist milieu triggered the growth of bacteria [35]. An appropriate dressing preparation should therefore be antimicrobial too, and honey appeared to have antibacterial properties, as confirmed in the 1990s, when a number of anti-inflammatory and antimicrobial mechanisms have been hypothesised with reference to it. According to Wahdan, different antimicrobial substances are present in honey [36]. In particular, inhibines appear to play a relevant role, including hydrogen peroxide, flavonoids and phenolic acids. Flavonoids had already been extracted from honey before, while it was only in the late 1990s that caffeic acid and ferulic acid (phenolic acids) were extracted from honey for the first time [36].

On clinical grounds, the evaluation of honey for wound healing has constituted a topic of a recent Cochrane review, as discussed above [1]. In that review, Jull et al. concluded that honey might shorten healing times in superficial and also partial thickness burns, if compared with different standard dressings. Such a confirmation appears to be precious for physicians, since it represents a cheap, effective and easy-toaccess alternative to available dressings. As in the case of many other substances, such as beverages including tea, coffee, wine and chocolate, popular beliefs regarding their putative preventive or therapeutic characteristics have been proved to be evidence-based, as confirmed by recent biomedical research and knowledge [37].

The importance of honey for human health, and not only concerning its dietary use, clearly emerged when its topic administration for burns treatment was analysed. The example of honey underlines the current relevance of past traditions regarding a number of "sweet" remedies, exactly when compared with modern scientific information. Therefore, and in conclusion, it is really true that one never learns enough from the past, and we believe that Archie Cochrane himself, the scientist after whom the Cochrane Collaboration and the Cochrane Review here discussed were named, would agree with that.

Conflict of interest statement The authors declare that they have no conflict of interest related to the publication of this manuscript.

\section{References}

1. Jull AB, Rodgers A, Walker N (2008) Honey as a topical treatment for wounds. Cochrane Database Syst Rev CD005083

2. Wasiak J, Cleland H, Campbell F (2008) Dressings for superficial and partial thickness burns. Cochrane Database Syst Rev CD002106

3. Balk EM, Bonis PA, Moskowitz H, Schmid CH, Ioannidis JP et al (2002) Correlation of quality measures with estimates of treatment effect in meta-analyses of randomized controlled trials. JAMA 287:2973-2982 
4. Campbell DT, Stanley JC (1963) Experimental and quasiexperimental designs for research. Rand McNally, Chicago

5. Subrahmanyam M (1993) Honey impregnated gauze versus polyurethane film (OpSite) in the treatment of burns-a prospective randomised study. Br J Plast Surg 46:322-323

6. Subrahmanyam M (1996) Honey dressing for burns-an appraisal. Ann Burns Fire Disasters IX:33-35

7. Subrahmanyam M (1999) Early tangential excision and skin grafting of moderate burns is superior to honey dressing: a prospective randomised trial. Burns 25:729-731

8. Subrahmanyam M (1991) Topical application of honey in treatment of burns. Br J Surg 78:497-498

9. Keswani MH, Patil AR (1985) The boiled potato peel as a burn wound dressing: a preliminary report. Burns Incl Therm Inj 11:220-224

10. Keswani MH, Vartak AM, Patil A, Davies JW (1990) Histological and bacteriological studies of burn wounds treated with boiled potato peel dressings. Burns 16:137-143

11. Dattatreya RM, Nuijen S, van Swaaij AC, Klopper PJ (1991) Evaluation of boiled potato peel as a wound dressing. Burns $17: 323-328$

12. Subrahmanyam M (1996) Honey dressing versus boiled potato peel in the treatment of burns: a prospective randomized study. Burns 22:491-493

13. Subrahmanyam M (1994) Honey-impregnated gauze versus amniotic membrane in the treatment of burns. Burns 20:331-333

14. Subrahmanyam M (1996) Addition of antioxidants and polyethylene glycol 4000 enhances the healing property of honey in burns. Ann Burns Fire Disasters IX:93-95

15. Gore MA, Akolekar D (2003) Evaluation of banana leaf dressing for partial thickness burn wounds. Burns 29:487-492

16. Ahmed AK, Hoekstra MJ, Hage JJ, Karim RB (2003) Honeymedicated dressing: transformation of an ancient remedy into modern therapy. Ann Plast Surg 50:143-147 discussion 147-148

17. Lay-Flurrie K (2008) Honey in wound care: effects, clinical application and patient benefit. Br J Nurs 17:S30, S32-36

18. Simon A, Traynor K, Santos K, Blaser G, Bode U, Molan P (2008) Medical honey for wound care still the 'latest resort'? Evid Based Complement Alternat Med

19. Guilbaud J (1992) European comparative clinical study of Inerpan: a new wound dressing in treatment of partial skin thickness burns. Burns 18:419-422

20. Guilbaud J, Honde C (1993) Multicentre comparative clinical study of a new wound dressing: PA286 (Inerpan). Eur J Plast Surg 16:73-76

21. Bugmann P, Taylor S, Gyger D, Lironi A, Genin B, Vunda A, La Scala G, Birraux J, Le Coultre C (1998) A silicone-coated nylon dressing reduces healing time in burned paediatric patients in comparison with standard sulfadiazine treatment: a prospective randomized trial. Burns 24:609-612

22. Gotschall CS, Morrison MI, Eichelberger MR (1998) Prospective, randomized study of the efficacy of Mepitel on children with partial-thickness scalds. J Burn Care Rehabil 19:279-283
23. Barret JP, Dziewulski P, Ramzy PI, Wolf SE, Desai MH, Herndon DN (2000) Biobrane versus 1\% silver sulfadiazine in seconddegree pediatric burns. Plast Reconstr Surg 105:62-65

24. Gerding RL, Imbembo AL, Fratianne RB (1988) Biosynthetic skin substitute vs. $1 \%$ silver sulfadiazine for treatment of inpatient partial-thickness thermal burns. J Trauma 28:1265-1269

25. Gerding RL, Emerman CL, Effron D, Lukens T, Imbembo AL, Fratianne RB (1990) Outpatient management of partial-thickness burns: Biobrane versus 1\% silver sulfadiazine. Ann Emerg Med 19:121-124

26. Lal S, Barrow RE, Wolf SE, Chinkes DL, Hart DW, Heggers JP, Herndon DN (2000) Biobrane improves wound healing in burned children without increased risk of infection. Shock 14:314-318 discussion 318-319

27. Curreri PW, Desai MH, Bartlett RH, Heimbach DM, Parshley P, Trunkey D (1980) Safety and efficacy of a new synthetic burn dressing: a multicenter study. Arch Surg 115:925-927

28. Husain MT, Akhtar M, Akhtar N (1983) Report on evaluation of hydron film as burn wound dressing. Burns Incl Therm Inj 9:330 334

29. Li XL, Huang YS, Peng YZ, Liao ZJ, Zhang GA, Liu Q, Tang J, Liu XS, Luo QZ (2006) [Multi-center clinical study of acticoat (nanocrystalline silver dressing) for the management of residual burn wounds]. Zhonghua Shao Shang Za Zhi 22:15-18

30. Wyatt D, McGowan DN, Najarian MP (1990) Comparison of a hydrocolloid dressing and silver sulfadiazine cream in the outpatient management of second-degree burns. J Trauma 30:857865

31. Poulsen TD, Freund KG, Arendrup K, Nyhuus P, Pedersen OD (1991) Polyurethane film (Opsite) vs. impregnated gauze (Jelonet) in the treatment of outpatient burns: a prospective, randomized study. Burns 17:59-61

32. Caruso DM, Foster KN, Blome-Eberwein SA, Twomey JA, Herndon DN, Luterman A, Silverstein P, Antimarino JR, Bauer GJ (2006) Randomized clinical study of Hydrofiber dressing with silver or silver sulfadiazine in the management of partial-thickness burns. J Burn Care Res 27:298-309

33. Cassidy C, St Peter SD, Lacey S, Beery M, Ward-Smith P, Sharp RJ, Ostlie DJ (2005) Biobrane versus duoderm for the treatment of intermediate thickness burns in children: a prospective, randomized trial. Burns 31:890-893

34. Bell SG (2007) The therapeutic use of honey. Neonatal Netw 26:247-251

35. Khan FR, Ul Abadin Z, Rauf N (2007) Honey: nutritional and medicinal value. Int J Clin Pract 61:1705-1707

36. Wahdan HA (1998) Causes of the antimicrobial activity of honey. Infection 26:26-31

37. Conti AA (2008) Coffee or tea? From the historically alleged curative properties of common beverages to their current evidence-based benefits on human health. In: Bernhardt NE, Kasko AM (eds) Nutrition for middle aged and elderly. Nova Science Publishers, New York, pp 1-10 